\title{
Mapping Dopamine Function in Primates Using Pharmacologic Magnetic Resonance Imaging
}

\author{
Bruce G. Jenkins, ${ }^{1}$ Rosario Sanchez-Pernaute, ${ }^{3}$ Anna-Liisa Brownell, ${ }^{2}$ Yin-Ching Iris Chen, ${ }^{1,2}$ and Ole Isacson ${ }^{3}$ \\ ${ }^{1}$ Massachusetts General Hospital (MGH) Nuclear Magnetic Resonance Center, Athinoula A. Martinos Center for Biomedical Imaging and ${ }^{2} \mathrm{MGH}$ Positron \\ Emission Tomography Center, Massachusetts General Hospital, Boston, Massachusetts 02129, and ${ }^{3}$ Neuroregeneration Laboratory, McLean Hospital, \\ Belmont, Massachusetts 02478
}

\begin{abstract}
Dopamine (DA) receptors play a central role in such diverse pathologies as Parkinson's disease, schizophrenia, and drug abuse. We used an amphetamine challenge combined with pharmacologic magnetic resonance imaging (phMRI) to map DA-associated circuitry in nonhuman primates with high sensitivity and spatial resolution. Seven control cynomolgous monkeys and 10 MPTP (1-methyl-4-phenyl1,2,3,6-tetrahydropyridine)-treated parkinsonian primates were studied longitudinally using both positron emission tomography (PET) and phMRI. Amphetamine challenge ( $2.5 \mathrm{mg} / \mathrm{kg}$, i.v.) in control monkeys increased relative cerebral blood volume ( $\mathrm{rCBV})$ in a number of brain regions not described previously, such as parafascicular thalamus, precentral gyrus, and dentate nucleus of the cerebellum. With the high spatial resolution, we were also able to readily identify changes in $\mathrm{rCBV}$ in the anterior cingulate, substantia nigra, ventral tegmental area, caudate (tail and head), putamen, and nucleus accumbens. Amphetamine induced decreases in rCBV in occipital and posterior parietal cortices. Parkinsonian primates had a prominent loss of response to amphetamine, with relative sparing of the nucleus accumbens and parafascicular thalamus. There was a significant correlation between rCBV loss in the substantia nigra and both PET imaging of dopamine transporters and behavioral measures. Monkeys with partial lesions as defined by $2 \beta$-carbomethoxy-3 $\beta$-(4fluorophenyl) tropane binding to dopamine transporters showed recruitment of premotor and motor cortex after amphetamine stimulus similar to what has been noted in Parkinson's patients during motor tasks. These data indicate that phMRI is a powerful tool for assessment of dynamic changes associated with normal and dysfunctional DA brain circuitry in primates.
\end{abstract}

Key words: amphetamine; dopamine; MRI; macaque; Parkinson's disease; PET

\section{Introduction}

The neurotransmitter dopamine (DA) and DA receptors play a crucial role in diverse pathologies such as schizophrenia, drug abuse, and Parkinson's disease. In particular, in Parkinson's disease, the loss of DA neurons in the pars compacta of the substantia nigra results in profound changes in subcortical and cortical structures integrated in the motor loops that control motor planning and execution (Marsden and Obeso, 1994). Although some of these changes are directly related to the loss of DA in the striatal projection areas, other changes occur downstream and may reflect direct or adaptive postsynaptic responses in nondopaminergic pathways (Brooks, 1999). Typically, DA transmitter changes have been visualized using autoradiography and positron emission tomography (PET). Recent work has shown that DA function can be evaluated using magnetic resonance imaging (MRI) techniques in rats, monkeys, and humans (Q. Chen et al., 1996,

Received April 23, 2004; revised Sept. 3, 2004; accepted Sept. 7, 2004.

This work was supported by National Institute of Neurological Disorders and Stroke Grant NS-39793, United States Army Medical Research and Material Command Grants DAMD17-01-1-0762 and DAMD17-98-1-8618 (0.I.), New England Regional Primate Research Center Grant P51RR00168, and National Institute on Drug Abuse Grants DA-16187A and DA-09467.

Correspondence should be addressed to Bruce G. Jenkins, Massachusetts General Hospital Nuclear Magnetic Resonance Center, Building 149, 13th Street, Charlestown, MA 02129. E-mail: bgj@nmr.mgh.harvard.edu. DOI:10.1523/JNEUROSCI.1558-04.2004

Copyright $\odot 2004$ Society for Neuroscience $\quad$ 0270-6474/04/249553-08\$15.00/0
1999; Breiter et al., 1997; Y. I. Chen et al., 1997; Marota et al., 2000; Stein, 2001; Zhang et al., 2001; Honey et al., 2003). Large changes in either blood oxygenation level dependent (BOLD) or relative cerebral blood volume (rCBV) can be induced by administration of the DA releaser amphetamine or the DA transporter (DAT) blockers cocaine and $2 \beta$-carbomethoxy- $3 \beta$ - $(4$ fluorophenyl) tropane (CFT). These compounds lead to a large increase in synaptic DA levels. The increased rCBV or BOLD signal intensity after administration of these ligands to control animals correlates temporally with DA release measured using microdialysis (Y. I. Chen et al., 1997, 1999; Jenkins et al., 2002) and is not correlated with changes in systemic physiologic variables or $\mathrm{pCO}_{2}$. Furthermore, loss of DA cells induced using unilateral 6-hydroxydopamine (6-OHDA) lesioning leads to a decrease in response to both amphetamine and the cocaine analog CFT (Y. I. Chen et al., 1997, 1999). Recovery of dopaminergic function after transplantation of either fetal dopamine cells or stem cells can be assessed using MRI with a pharmacological challenge (Y. I. Chen et al., 1999; Bjorklund et al., 2002). Dopamine receptor supersensitivity can also be measured using pharmacological MRI (phMRI) in the 6-OHDA model after the administration of apomorphine, showing good correlation with PET studies in the same animals (Nguyen et al., 2000). Other work using the BOLD effect showed that the response to L-DOPA is more pronounced on the lesion side in unilaterally MPTP (1- 
methyl-4-phenyl-1,2,3,6-tetrahydropyridine)-lesioned primates (Q. Chen et al., 1996, 1999).

Based on previous work in rodents, we hypothesized that amphetamine administration would allow us to probe not only the degree of dopamine cell loss but also to assess changes in the dopamine and downstream circuitry in a primate brain.

In this work, we investigate how the hemodynamic changes evoked by amphetamine can be mapped with phMRI in normal and MPTP-treated parkinsonian primates and use combined PET and behavioral testing to assess the degree of DA loss. In control primates, using the high sensitivity of the increased relaxivity with iron oxide nanoparticles (IRON) technique (Mandeville et al., 1998, 2001; Y. C. Chen et al., 2001), we were able to observe distinct regional activation by amphetamine at a much higher resolution than any previous in vivo techniques. In parkinsonian primates, we could determine the effects of selective DA denervation and the relative sparing of regions innervated by the A10 neurons, previously only described using postmortem histology (Chiueh et al., 1985; Schneider et al., 1987; Alexander et al., 1992; German et al., 1992).

\section{Materials and Methods}

Animals. Seven control and 10 MPTP-lesioned cynomolgus monkeys (Macaca fascicularis, 4-5 years of age) were studied. Animals were housed at the New England Regional Primate Center according to International Animal Care and Use Committee guidelines. MPTP lesioning was performed using $0.3-0.5 \mathrm{mg} \cdot \mathrm{kg}^{-1} \cdot$ week $^{-1}$ intravenously (the average cumulative dose of MPTP was $21 \pm 4.4 \mathrm{mg}$ in 6 months) until parkinsonian signs appeared. Symptoms appeared gradually over 2 months and persisted after MPTP interruption. Animals developed all of the classical signs of Parkinson's disease, including bradykinesia, hypokinesia, rigidity, tremor, and posture and balance abnormalities. Animals were rated according to a scale based on the motor subscale of the Unified Parkinson's Disease Rating Scale, similar to other motor scales used in parkinsonian primates (Imbert et al., 2000). The following signs were scored from 0 to 3: bradykinesia in the left and right arms (L/R), tremor $\mathrm{L} / \mathrm{R}$, rigidity $\mathrm{L} / \mathrm{R}$, hypokinesia, and posture/balance (total score from 0 to 24). Evaluation of motor behavior was complemented by a computerized timed task using the motor activity panel (MAP) test (Gash et al., 1999). We used the straight rod task of the MAP test (Gash et al., 1999) in which the animal has to retrieve a candy reward inserted onto a rod, computing the time used to retrieve the treat for each arm independently. In addition, we collected baseline global motor activity using activity monitors (Actiwatch; Mini-Mitter, Bend, OR). Both tests provide objective measures of bradykinesia and hypokinesia, respectively, and are sensitive to MPTP-induced motor deficit in macaques (Bankiewicz et al., 1999).

PET studies. PET studies using the dopamine transporter analog ${ }^{11} \mathrm{C}$ CFT were performed as described previously (Brownell et al., 1996, 1998a) to evaluate the degree of DAT loss $\sim 8$ weeks after the last dose of MPTP. The binding potential (BP) of CFT in the posterior putamen was calculated, and these data were correlated with behavioral indices using regression analysis and also with changes in amphetamine-induced rCBV signal (see below).

MRI studies. MRI studies were performed on a Siemens (Erlangen, Germany) 3T Allegra system using a home-built transmit-receive 3 inch surface coil. The animal's head was placed in the center of the surface coil such that the coil fit over the skull, above the eyes. For MRI studies, animals were first sedated with a small dose of ketamine ( $15 \mathrm{mg} / \mathrm{kg}$, i.m.), intubated, and placed in a head frame in the magnet. They were subsequently anesthetized with halothane gas $(1-1.5 \%)$ but were free breathing. Animals were kept warm with a $38^{\circ} \mathrm{C}$ circulating water blanket. End tidal $\mathrm{CO}_{2}$ was continuously monitored. Initially, in some animals, the heart rate and oxygen saturation were also continuously monitored to determine the effect of amphetamine on physiological parameters. Imaging was performed using the IRON technique (Mandeville et al., 1998, 2001; Y. C. Chen et al., 2001). Briefly, continuous gradient echo imaging [repetition time and echo time, 500 and $18 \mathrm{msec}$; flip angle, $70^{\circ}$; field of view, $160 \mathrm{~mm}$; phase encode steps, $256 \times 192$ ] was performed with 202 $\mathrm{mm}$ slices and an in-plane resolution of $0.63 \times 0.83 \mathrm{~mm}$. After collection of 6-10 baseline images, $10-15$ more images were acquired after intravenous administration of $10 \mathrm{mg} / \mathrm{kg}$ monocrystalline iron oxide nanoparticles. Then D-amphetamine $(2.5 \mathrm{mg} / \mathrm{kg})$ was administered intravenously, and imaging continued for 40-60 min.

The IRON technique at $3 \mathrm{~T}$ produces contrast-to-noise ratios for the amphetamine-induced activation that are a factor of approximately six times larger than that of BOLD imaging at the same field strength (Y. C. Chen et al., 2001; Mandeville et al., 2001; Vanduffel et al., 2001). This is the equivalent of averaging many animals $(\approx 6-10)$ using the BOLD technique to produce a contrast-to-noise ratio similar to one IRON image.

Processing of the data was performed using region of interest (ROI)based analyses of regional changes in $\mathrm{rCBV}$. Images were converted to maps of changes in rCBV by converting image intensities on a pixel-bypixel basis to $\Delta \mathrm{R} 2^{\star}$ (transverse relaxation) as $\Delta \mathrm{R} 2^{*}=-\ln \left(S / S_{0}\right) / \mathrm{TE}$. Changes in rCBV are directly proportional to changes in $\Delta \mathrm{R} 2^{*}$ (Villringer et al., 1988; Belliveau et al., 1991).

ROIs were drawn for brain regions corresponding to caudate (excluding the tail), putamen, thalamus, precentral gyrus (PRG), anterior cingulate, occipital cortex, motor cortex (hand area), substantia nigra, and ventral tegmental-red nucleus area. The ROIs for cortical regions were outlined with reference to the macaque brain atlas (University of Washington, Seattle, WA). The matching coordinates were as follows for the PRG: anterior commissure, +5 ; right left (RL), 20; and superior inferior (SI), +2.5 . For the cingulate cortex, the matching coordinates were as follows: $\mathrm{AC},+2$; RL, \pm 1.5 ; SI, +11.5 . ROIs for the subcortical regions were drawn from segmentation of the functional images after injection of the contrast agent, which allowed precise delineation of subcortical structures in the functional images.

rCBV values were integrated over $30 \mathrm{~min}$ after amphetamine administration in the ROIs thresholded for significant changes in $\mathrm{rCBV}$ at a $p$ value of $<0.05$ using Student's $t$ test corrected for multiple voxels. Statistical parametric maps of $p$ values from Student's $t$ test were also made for illustration, but no data analysis was performed on these images. Comparison of changes in rCBV before and after MPTP lesioning was performed using a one-way ANOVA.

\section{Results}

\section{Amphetamine administration to control macaques}

Administration of amphetamine to healthy, anesthetized primates led to marked changes in rCBV in areas with high dopamine receptor density as well as in associated circuitry (shown in a coronal orientation) (Fig. 1). We obtained statistical and parametric maps of changes in rCBV after administration of 2.5 $\mathrm{mg} / \mathrm{kg}$ amphetamine in seven control (naive) macaques (Figs. 1, 2 ). Changes in rCBV are summarized in Table 1. The largest increases in rCBV were noted in parafascicular thalamus, nucleus accumbens, putamen, caudate, substantia nigra, and ventral tegmental-red nucleus area. Smaller changes were noted in inferior PRG, anterior cingulate, superior temporal gyrus (STG), and insular cortex (Table 1; Figs. 1, 2). There were small ( $\approx 10 \%)$ negative $\mathrm{rCBV}$ changes in most areas of posterior cortex, such as occipital and parietal cortex (Fig. 2, Table 1). The changes in rCBV in the brainstem areas such as substantia nigra and the red nuclei are easier to delineate in the transaxial orientation shown in Figure 2; thus, most studies were collected in this orientation. The changes in rCBV were not related to an effect of amphetamine on global physiological parameters because mean $\mathrm{EtCO}_{2}$ was $37.5 \pm 1.5$ before, versus $38.3 \pm 2.9$ after, amphetamine $(p>$ 0.05 ) in the control monkeys. As reported previously in rats (Y. I. Chen et al., 1997), the average heart rate is transiently increased by amphetamine but returns to baseline before the amphetamine-induced signal changes do. The average heart rate at baseline was $104 \pm 13$. In the $2-5 \mathrm{~min}$ after amphetamine, 
1

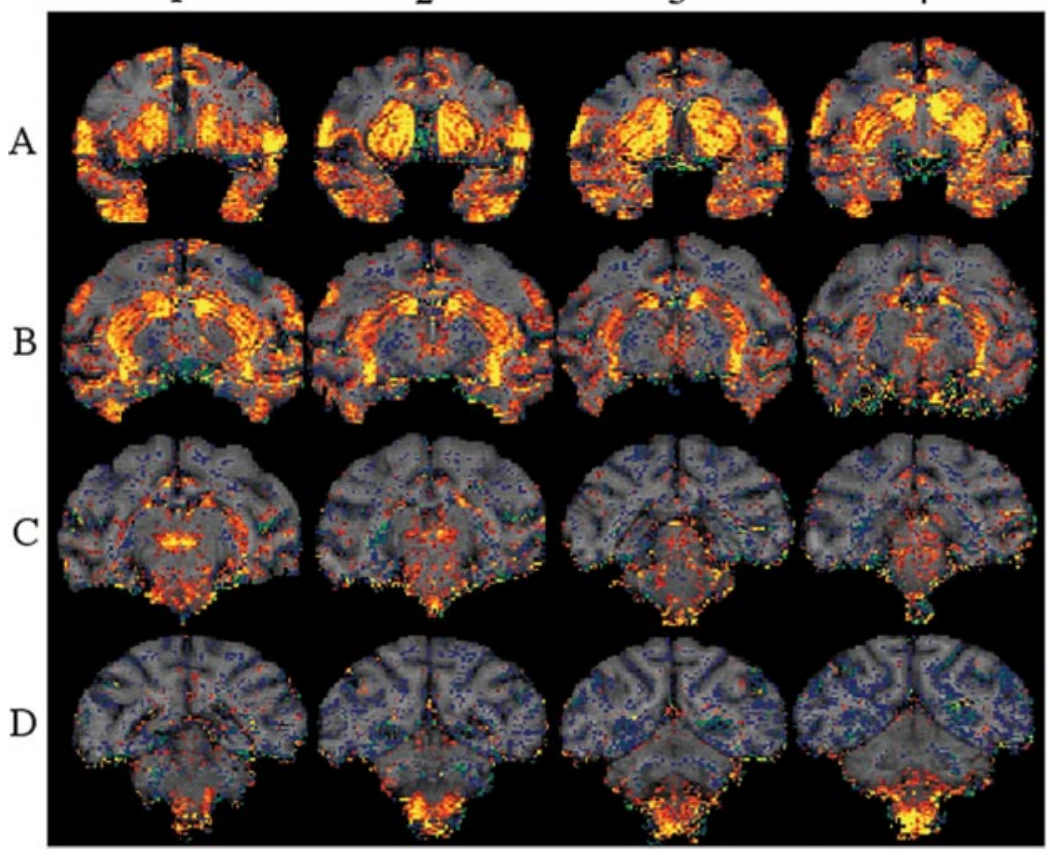

$r C B V$

40

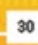

30

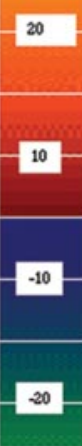

Figure 1. Parametric map of rCBV change induced by $2.5 \mathrm{mg}$ of amphetamine in a control macaque. Serial coronal slices ( $2 \mathrm{~mm}$ thick from anterior to posterior) demonstrate prominent responses in many dopaminoceptive regions. Large r(BV increases are seen in the putamen and caudate (including the tail of the caudate seen in $B 1, B 2)$, the parafascicular thalamus ( $C 1)$, the anterior cingulate $(A 1-A 4)$, the precentral gyrus $(A 1-A 4)$, and the brainstem nuclei, including the substantia nigra, the ventral tegmental area, and red nuclei $(B 3, B 4, C 1, C 2, D 1, D 2)$. Smaller decreases in rCBV were noted in the posterior parietal cortex and occipital cortex (D1-D4). The color bar represents the average rCBV change between 0 and 30 min after amphetamine. Red-yellow represent increases in rCBV, whereas blue-green represent decreased rCBV.
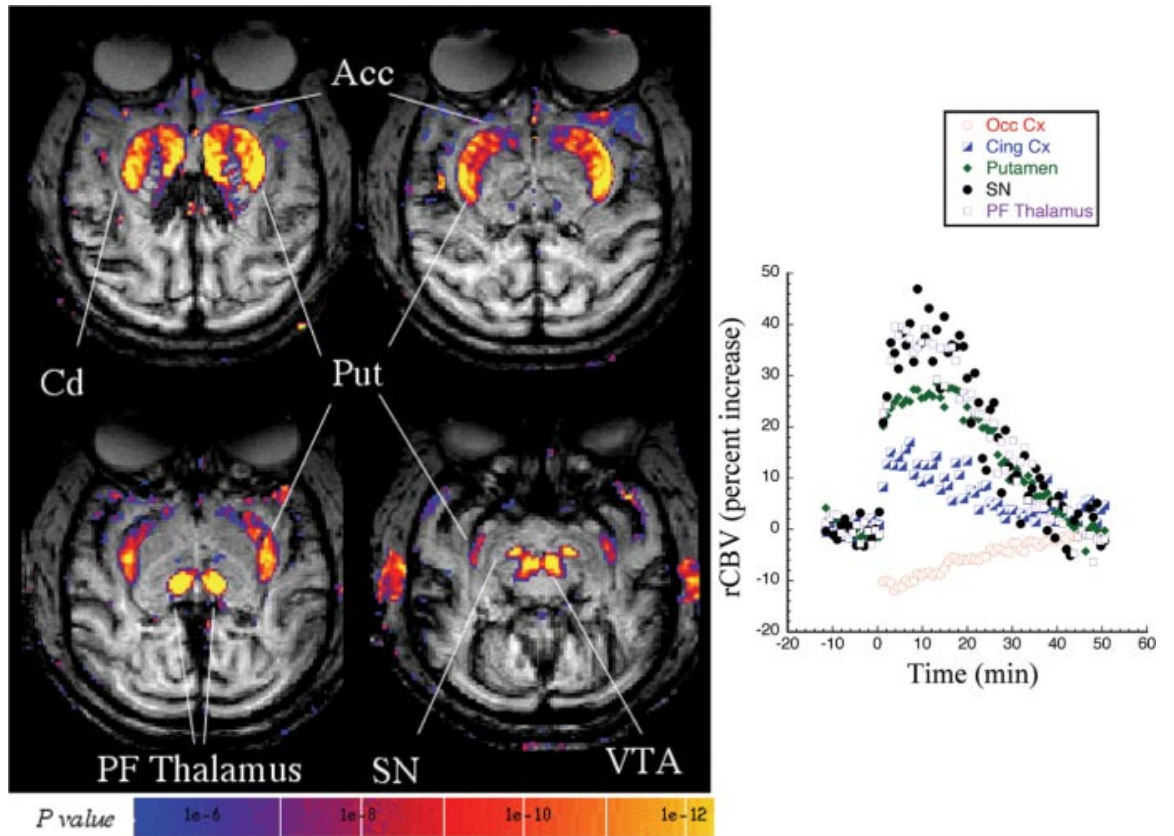

Figure 2. A statistical parametric map ( $t$ test; left) of significant $r C B V$ increases in a control macaque ( $2.5 \mathrm{mg} / \mathrm{kg}$ amphetamine) acquired in the transaxial plane. Large increases in $\mathrm{rCBV}$ are seen in the same regions as the coronal orientation shown in Figure 1 but are much better delineated in the brainstem nuclei [substantia nigra (SN), ventral tegmental area (VTA)] in this orientation. Shown on the right is the time course of $\mathrm{rCBV}$ changes after amphetamine at time 0 in selected brain regions, including occipital cortex (Occ $(x)$, anterior cingulate cortex (Cing $(x)$, putamen (Put), SN, and parafascicular thalamus (PF Thalamus). The amphetamine-induced changes returned to baseline in $\sim 50 \mathrm{~min}$. For the sake of clarity, only positive $\mathrm{rCBV}$ changes are shown in this image. heart rate increased to $132 \pm 13$, and, after 10-15 $\mathrm{min}$, the heart rate returned to $113 \pm 6$. These changes did not correlate with the amphetamine-induced signal changes because the rCBV changes persist much longer than this. A lower dose of amphetamine $(1.5 \mathrm{mg} / \mathrm{kg})$ produced a similar pattern of rCBV changes to that shown for $2.5 \mathrm{mg} / \mathrm{kg}$ (Fig. 2), except for a smaller magnitude of rCBV changes (data not shown).

\section{Amphetamine administration to} MPTP-treated parkinsonian macaques Ten animals were scanned after repeated intravenous MPTP administration at least 2 months after the last dose. Most animals included in this study were overtly parkinsonian $(n=8)$ and had motor scores $\geq 10$ in the parkinsonian primate scale. Two animals showed mild symptoms despite a marked reduction in DA striatal terminals as measured by PET and ${ }^{11} \mathrm{C}-\mathrm{CFT} \mathrm{BP}$, and one was asymptomatic and had a $27 \%$ decrease in ${ }^{11} \mathrm{C}$-CFT BP (see supplemental material, available at www.jneurosci.org). The average ${ }^{11} \mathrm{C}$-CFT BP in the putamen before MPTP exposure was $3.17 \pm 0.3$ (Fig. 3a,b). After MPTP administration was completed in this group of animals, the average $\mathrm{BP}$ was $1.67 \pm 0.47(p<$ $10^{-7}$ ) (Fig. 3a,b). The MPTP effect on motor performance was also assessed by computerized recording of global motor activity and a timed motor task (Gash et al., 1999). After MPTP administration, the animals showed a significant decrease in global activity (Fig. 3c) and a significant increase in the time used to perform a computerized reaching task (Fig. 3d).

In most parkinsonian primates, there was an almost complete loss of amphetamine-induced rCBV MRI signal changes in DA regions (Fig. 4, Table 1). Shown in Figure 4 are the changes 4 months after cessation of MPTP treatment (Fig. $4 b$ ). This is representative of the animals studied after MPTP administration. The time course of the rCBV changes in putamen in this animal is shown in Figure $4 c$, before and after MPTP lesioning. Most notable in these parkinsonian primates was the maintenance of a robust $\mathrm{rCBV}$ response in the nucleus accumbens (Fig. 4b) whereas the caudateputamen and nigral activation had decreased to noise level. There was also a relative preservation of the $\mathrm{rCBV}$ response to amphetamine in the parafascicular thalamus, as well as in the STG (Fig. 4, Table 1). The pattern of changes observed was not attributable to changes in physiologic variables. After MPTP treatment, the 
average $\mathrm{EtCO}_{2}$ was $34.8 \pm 3.1$ before amphetamine and $35.3 \pm 2.9$ after (not significant). The average heart rate at baseline in the MPTP-treated animals was $112 \pm 11$. In the $2-5$ min after amphetamine, the heart rate increased to $146 \pm$ 13 , and, after $10-15 \mathrm{~min}$, the heart rate returned to $116 \pm 3$.

Two of the 10 animals showed a different pattern. The first of these animals not only showed a robust response to amphetamine but also showed recruitment of motor areas not seen in the normal controls (see supplemental material, available at www.jneurosci.org). This animal had only a partial lesion, as shown by ${ }^{11} \mathrm{C}$-CFT binding (which was decreased only by 27\%). The other animal, however, showed a marked decrease in ${ }^{11} \mathrm{C}$-CFT BP (BP of 1.13 ) and was parkinsonian (motor score of 16). Despite this, there was a robust response to amphetamine similar to the partially lesioned animal with recruitment of motor and premotor cortex. In contrast, there was almost no rCBV change in substantia nigra (see supplemental material, available at www.jneurosci.org). A repeat study of this animal confirmed these results.

We examined the relationship between rCBV changes, DA parameters measured by PET, and behavior. There was a good relationship between ${ }^{11} \mathrm{C}$-CFT $\mathrm{BP}$ and rCBV changes after amphetamine (Fig. $5 a)$. Naive animals had a normal ${ }^{11} \mathrm{C}$-CFT $\mathrm{BP}$ in the posterior putamen $(2.8-3.5)$ and $\mathrm{rCBV}$ response above $20 \%$ change in putamen and substantia nigra. MPTPtreated animals with parkinsonism had reduced values of ${ }^{11} \mathrm{C}$-CFT BP in the posterior putamen and significantly diminished rCBV changes in response to amphetamine in these regions (Fig. 5a). Thus, changes measured using phMRI and PET corresponded to the normal and parkinsonian state of the animal. The threshold for onset of motor symptoms was an $\sim 30 \%$ decrease in BP (DA terminal loss). There was a significant correlation between the parkinsonian motor score and the putaminal ${ }^{11} \mathrm{C}$-CFT BP and the amphetamine-induced change in rCBV in the substantia nigra (Fig. $5 b$ ) not observed in any other brain region.

\section{Discussion}

In the intact anesthetized primate brain, amphetamine administration induced marked changes in rCBV in the mesonigrostriatal and corticostriatothalamic circuitry involved in reward and motor functions. The pattern of activation we observed in naive monkeys appeared to be related to the direct release of dopamine in areas with a high density of dopamine receptors (striatal, limbic, and midbrain regions) and, in addition, in several downstream areas, notably, in the intralaminar posterior nuclei of the

a)

b)
Table 1. Amphetamine-induced changes in rCBV in both naive and MPTP-treated animals

\begin{tabular}{lcccc}
\hline Structure & rCBV change naive & $\begin{array}{l}\text { rCBV change } \\
\text { after MPTP }\end{array}$ & Percentage change & $p$ value \\
\hline Occipital Cx & $-8.0 \pm 2.8$ & $-11.9 \pm 5.7$ & & NS \\
Motor CX & $0.1 \pm 5.9$ & $-4.6 \pm 7.5$ & & NS \\
Superior temporal gyrus & $19.0 \pm 4.9$ & $18.3 \pm 9.6$ & & NS \\
Cingulate Cx & $14.4 \pm 4.9$ & $7.4 \pm 6.1$ & -48.5 & $<0.01$ \\
Precentral gyrus & $21.6 \pm 8.4$ & $2.5 \pm 7.3$ & -88.3 & $<10^{-3}$ \\
Insular Cx & $7.7 \pm 7.4$ & $0.0 \pm 6.1$ & -99.9 & $<0.05$ \\
Globus pallidus & $-7.0 \pm 2.9$ & $-7.7 \pm 5.4$ & & $\mathrm{NS}$ \\
Nucleus accumbens & $19.1 \pm 4.9$ & $12.1 \pm 7.2$ & -36.9 & $<0.05$ \\
Parafascicular thalamus & $29.6 \pm 6.7$ & $14.6 \pm 15.0$ & -50.5 & $<0.05$ \\
Putamen & $25.2 \pm 2.9$ & $3.5 \pm 10.2$ & -86.1 & $<10^{-3}$ \\
Caudate & $23.6 \pm 6.4$ & $2.2 \pm 5.2$ & -90.8 & $<10^{-5}$ \\
Red nucleus & $21.6 \pm 8.3$ & $-1.3 \pm 9.4$ & -106.0 & $<10^{-3}$ \\
VTA & $30.9 \pm 16.7$ & $0.1 \pm 8.2$ & -99.8 & $<0.01$ \\
Substantia nigra & $28.7 \pm 7.6$ & $-3.5 \pm 5.6$ & -112.4 & $<10^{-6}$ \\
Dentate nucleus cerebellum & $9.5 \pm 3.2$ & $-0.9 \pm 8.1$ & -108.9 & $<0.05$ \\
\hline
\end{tabular}

Changes in rCBV are reported for the average over $30 \mathrm{~min}$ after amphetamine administration. These data represent animals studied at $2.5 \mathrm{mg} / \mathrm{kg}$ amphetamine. Ten animals were treated with MPTP. One was excluded from this table because the animal was scanned with $1.5 \mathrm{mg} / \mathrm{kg}$ amphetamine. The other animal excluded from the table was the animal with only a partial lesion and no symptoms. C, Cortex; VTA, ventral tegmental area.

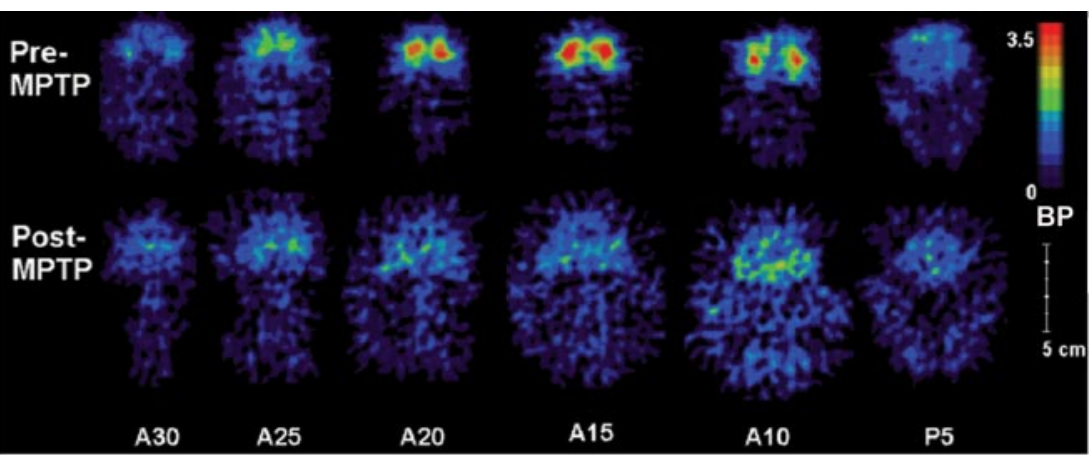

c)
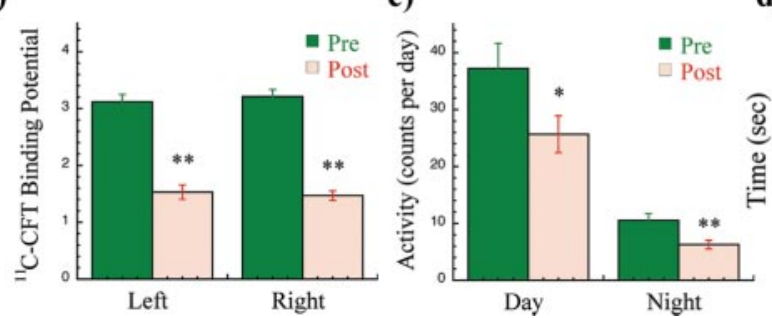

d)

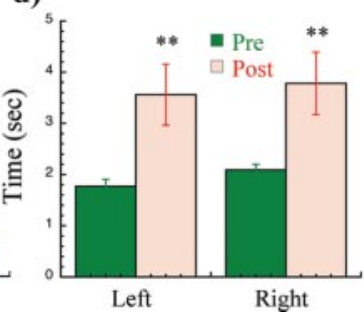

Figure 3. PET and behavioral data in the macaques. Typical ${ }^{11} \mathrm{C}-\mathrm{CFT}$ PET coronal images of dopamine transporter binding are shown before and after MPTP lesioning ( $a$ ). After MPTP, binding potential was decreased on average by $52 \pm 11 \%(b)$. Average global locomotor activity $(c)$ measured by automated activity monitors was decreased after the lesion, and the time to perform a computerized reaching task $(d)$ was significantly increased.

thalamus [centromedian-parafascicular ( $\mathrm{Cm}-\mathrm{PF})$ complex]. The latter area is particularly enriched in dopamine $\mathrm{D}_{5}$ receptors (Meador-Woodruff et al., 1992; Choi et al., 1995) that may contribute to the large increase in rCBV seen in the control animals. These data support the notion that hemodynamic changes occur in relation to synaptic activity. The level of detail achieved in these studies would be nearly impossible to see in BOLD images at $3 \mathrm{~T}$ and requires the IRON method because of its greatly increased contrast-to-noise ratio over BOLD (Mandeville et al., 1998, 2001; Y. C. Chen et al., 2001; Dubowitz et al., 2001; Vanduffel et al., 2001).

We showed previously that there is a tight correlation in time and relative amplitude between the hemodynamic 


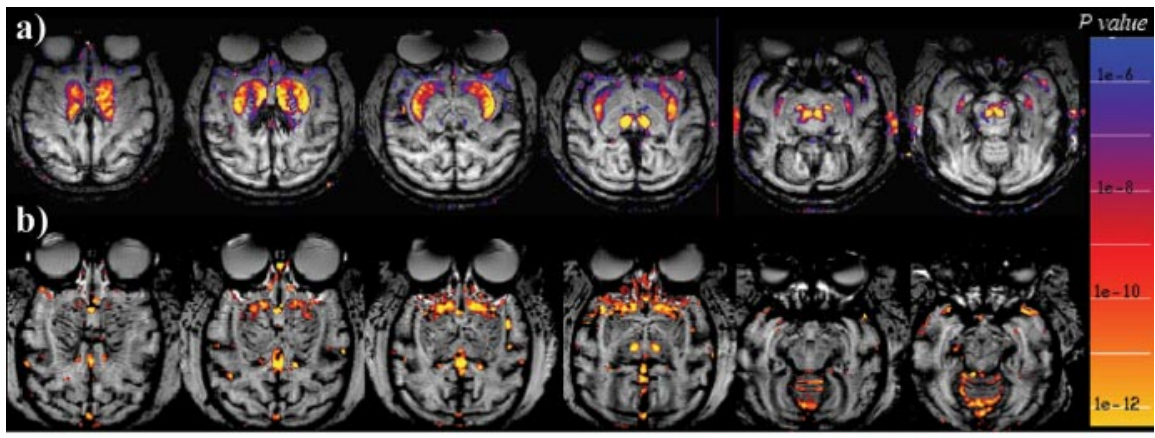

c)

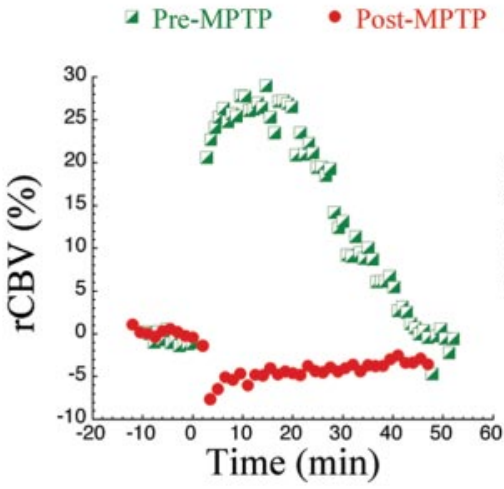

changes induced by amphetamine or the DAT blocker CFT on the lesioned side in rats unilaterally injected with 6-OHDA (Y. I. Chen et al., 1997, 1999; Nguyen et al., 2000). The latter observation is important because other candidate neurovascular coupling agents such as acetylcholine, norepinephrine, or serotonin are intact in this model. As we demonstrated previously in rats (Y. I. Chen et al., 1997), there was no correlation between amphetamineinduced rCBV changes and heart rate changes.

A number of other studies examined amphetamine challenges in nonhuman primates and humans using both PET/ single-photon emission-computed tomography (SPECT) and MRI techniques. The PET/SPECT studies included imaging cerebral blood flow (CBF) changes as well as indirectly measuring dopamine release using raclopride displacement (Innis et al., 1992; Devous et al., 2001; Drevets et al., 2001; Zhang et al., 2001; Price et al., 2002; Martinez et al., 2003). In a SPECT study of awake humans, $0.4 \mathrm{mg} / \mathrm{kg}$ amphetamine increased CBF in many of the same regions we observed in the anesthetized primates, including brainstem, anterior thalamus, and frontal cortex (Devous et al., 2001). That study found decreased CBF in occipital and parietal cortices, similar to our observation of decreased rCBV in these areas (Fig. 1, Table 1). The areas of decreased activation are interesting, and we have no explanation for them as yet. However, as shown in Table 1, the decreased activation was not affected by MPTP treatment. Because MPTP treatment caused almost complete loss of rCBV changes in the striatum and frontal cortex, it is unlikely that the negative changes reflect "vascular steal." Studies of isofluorane-anesthesized baboons led to observations of increased CBF in a pattern similar to our study, including increases in striatum with a peak change in CBF between 5 and 45 min after amphetamine (Price et al., 2002), although the poor temporal and spatial resolution of SPECT precludes a formal comparison. The strong similarities between the awake human and our results in halothane-anesthetized primates lend great credence to the utility of MRI studies in anesthetized animals. Furthermore, comparisons with rat studies show that the areas of increased glucose utilization after amphetamine adminis-

Figure 5. Relationships among PET, MRI, and motor behavior (parkinsonian score). The relationship between rCBV measu using MRI and binding potential measured using ${ }^{11} \mathrm{C}-\mathrm{CFT}$ PET both before and after MPTP treatment is shown in $a$ for putamen (Put) and substantia nigra (SN). There is a correlation between the PET and MRI between control and MPTP-treated groups. Also shown are the correlations after MPTP treatment between motor scores (behavior) and (FT binding potential and rCBV changes in the SN and CFT binding potential (b). The correlations were significant $(p<0.05)$.

changes induced by amphetamine in rat striatum and the extracellular dopamine measurements made using microdialysis (Y. I. Chen et al., 1997, 1999). These results suggest that the rCBV measurements are indirect measures of the ability to release dopamine. This finding was further supported by the loss of signal tration reported in the literature from awake animals (Wechsler and Sokoloff, 1979) agree with our rCBV measurements in halothane-anesthetized rats (Nguyen et al., 2000; Y. C. Chen et al., 2001). Notwithstanding the different temporal resolution of the two techniques, the results for the areas most affected by 
amphetamine are almost identical (striatum, insular cortex, and frontal cortex). A comparative study of the effects of different anesthetics on increased CBF after somatosensory stimulation in rats concluded that halothane anesthesia produced increases comparable with $\alpha$-chloralose anesthesia; however, the halothane results were noisier (Lindauer et al., 1993). Our results here and our published results in rodents suggest that halothane is a suitable anesthetic for observation of the effects of dopaminergic stimuli.

We published studies in rodents to show that the signal changes observed after amphetamine stimulation are not attributable to changes in heart rate and blood pressure (Y. I. Chen et al., 1997). Autoregulation of CBV and CBF is tightly controlled over the ranges of blood pressure and heart rate induced by amphetamine (Zaharchuk et al., 1999). Because the heart rate changes as a result of amphetamine in these monkeys were shorter than the rCBV changes, it is unlikely that these, or the associated blood pressure changes, are responsible for the rCBV changes noted. Furthermore, the effects of blood pressure and heart rate should be global, and we observed very focal rCBV changes after amphetamine.

We can analyze the findings of our present study with respect to DA function: (1) areas responsive to amphetamine and sensitive to MPTP, such as caudate, putamen, midbrain, insula, and precentral cortex, which are part of the DA nigrostriatal thalamocortical motor loop; (2) areas responsive to amphetamine and less sensitive to MPTP, such as nucleus accumbens, Cm-PF thalamus, and cingulate, part of the mesolimbic dopaminergic system, which is relatively spared in both MPTP-induced and idiopathic parkinsonism; and (3) areas responsive to amphetamine and insensitive to MPTP, such as the STG, or nonresponsive to amphetamine (e.g., globus pallidus).

The first group includes areas integrated in the motor circuitry. In this system, amphetamine-induced rCBV changes provide a measure of DA innervation, and changes in rCBV were markedly different between normal and parkinsonian primates. We found a noisy, but significant, correlation between ${ }^{11} \mathrm{C}-\mathrm{CFT}$ binding potential in the putamen and rCBV changes in both midbrain and striatum. CFT, a selective ligand for DAT, provides a validated measure of DA presynaptic terminals in monkeys (Hantraye et al., 1992). In MPTP-treated primates, severe reduction in ${ }^{11} \mathrm{C}$-CFT binding is correlated with development of motor symptoms (Brownell et al., 1998b). In Parkinson's patients, CFT has proven to be a sensitive marker for early stages of the disease (Frost et al., 1993) and for the rate of disease progression (Nurmi et al., 2000). However, CFT binding is a presynaptic DA measure, whereas rCBV changes induced by amphetamine require not only the release of DA but also a receptor-mediated effect of the neurotransmitter, synaptic or vascular or both, linked to a hemodynamic response. The fact that the correlation between CFT binding and amphetamine-induced $\mathrm{rCBV}$ is not absolute is seen by the modest correlation coefficients noted in Figure $5(R \approx 0.7)$ and by the fact that one monkey maintained a robust response to amphetamine after MPTP in two separate scans, despite a low ${ }^{11} \mathrm{C}$-CFT binding potential (see supplemental material, available at www.jneurosci.org). Future studies may well find a better correlation with ${ }^{18} \mathrm{~F}$-DOPA PET or DOPA responsiveness rather than with CFT binding.

The spatial resolution of this technique allowed the delineation of the response in the nucleus accumbens, demonstrating for the first time in vivo the selective toxicity of MPTP on the A9 DA neurons while preserving the A10 neurons. However, responses in both accumbens and cingulate cortex were moderately de- creased after MPTP, particularly in severely parkinsonian animals. The posterior intralaminar nuclei of the thalamus $(\mathrm{Cm}-\mathrm{PF}$ complex) are large in primates and heavily and reciprocally connected to the striatum (Matsumoto et al., 2001). Activation in these nuclei was also moderately reduced after MPTP administration, in agreement with their reciprocal connections from both the motor and the associative striatum. The strong activation of parafascicular thalamus has not been described previously, and rCBV changes were relatively preserved in parkinsonian primates. These results suggest that it may be more closely associated with the A10 rather than A9 circuitry.

In contrast to the activation seen in dopaminoceptive regions, the activation observed in the STG in naive animals was unaffected by MPTP. There are a number of possible explanations for this, including the possibility that the hemodynamic changes induced in this region may result from acetylcholine release (Hemsworth and Neal, 1968); however, we have no data bearing on the multiple interpretations. Finally, there were some regions that, despite being part of the DA basal ganglia motor loop, were not responsive to amphetamine. The most intriguing is the globus pallidus, which is the main output nucleus of projecting striatal GABA neurons. We observed small negative changes in $\mathrm{rCBV}$ in the globus pallidus that was not affected by MPTP administration (Table 1). This is consistent with our previous studies in rats in which we did not observe amphetamine-induced changes in rCBV in globus pallidus (Y. I. Chen et al., 1997, 1999; Nguyen et al., 2000; Jenkins et al., 2002). Another study, using BOLD imaging in awake young and aged primates (Zhang et al., 2001) showed that amphetamine caused external segment of the globus pallidus (GPe) BOLD signal to increase and internal segment of the globus pallidus (GPi) signal to decrease in aged rhesus monkeys. In young rhesus monkeys, BOLD signal showed a small decrease in GPe and GPi similar to what we found.

We previously used MRI to characterize in vivo amphetamine-related rCBV changes in the hemiparkinsonian, 6-OHDA lesioned rat that were correlated with motor scores, PET measurements of DAT binding, microdialysis measurements of dopamine release, and postmortem studies (Y. I. Chen et al., 1997, 1999; Nguyen et al., 2000; Jenkins et al., 2002). Similar to this study, we showed that there is almost a complete loss of amphetamine-induced signal changes in the lesioned hemisphere. We also identified, using amphetamine, local (striatal) and downstream (thalamic and cortical) activation related to successful engraftment of fetal and stem cells in hemiparkinsonian rats (Y. I. Chen et al., 1999; Bjorklund et al., 2002). In marked contrast to our findings in primates, activation in thalamocortical regions was completely abolished by 6-OHDA, a finding that likely reflects a difference in the model rather than a difference in circuitry.

In conclusion, we demonstrate that the use of an amphetamine challenge is a powerful new tool for mapping DA receptor loss in a primate Parkinson's disease model. The use of the IRON technique adds considerable statistical power compared with the BOLD technique. The use of $\mathrm{rCBV}$ changes in both nigra and striatum may provide an alternative and/or complementary tool to PET imaging for determining DA cell loss and dopaminergic function related to dopamine release. Such correlations between dopamine release measured using raclopride displacement and ${ }^{18}$ F-DOPA uptake have been observed previously in Parkinson's disease patients using PET (Piccini et al., 2003). Our experiments support the use of amphetamine phMRI as a probe in MPTPlesioned parkinsonian monkeys to provide insight into functional dynamic changes of the dopaminergic circuitry. 


\section{References}

Alexander GM, Schwartzman RJ, Brainard L, Gordon SW, Grothusen JR (1992) Changes in brain catecholamines and dopamine uptake sites at different stages of MPTP parkinsonism in monkeys. Brain Res 588:261-269.

Bankiewicz KS, Sanchez-Pernaute R, Oiwa Y, Kohutnicka M, Cummins A, Eberling J (1999) Preclinical models of Parkinson's disease. Curr Protoc Neurosci [Suppl 9]:9.4.1-9.4.32.

Belliveau JW, Kennedy DN, McKinstry RC, Buchbinder BR, Weisskoff RM, Cohen MS, Vevea JM, Brady TJ, Rosen BR (1991) Functional mapping of the human visual cortex by magnetic resonance imaging. Science 254:716-719.

Bjorklund LM, Sanchez-Pernaute R, Chung S, Andersson T, Chen IY, McNaught KS, Brownell AL, Jenkins BG, Wahlestedt C, Kim KS, Isacson O (2002) Embryonic stem cells develop into functional dopaminergic neurons after transplantation in a Parkinson rat model. Proc Natl Acad Sci USA 99:2344-2349.

Breiter H, Gollub R, Weisskoff R, Kennedy D, Makris N, Berke J, Goodman J, Kantor R, Gastfriend D, Riorden J, Mathew RT, Rosen BR, Hyman SE (1997) Acute effects of cocaine on human brain activity and emotion. Neuron 19:591-611.

Brooks DJ (1999) Functional imaging of Parkinson's disease: is it possible to detect brain areas for specific symptoms? J Neural Transm Suppl 56:139-153.

Brownell AL, Elmaleh D, Meltzer P, Shoup TM, Brownell GL, Fischman AJ, Madras BK (1996) Cocaine congeners as PET imaging probes for dopamine terminals. J Nucl Med 37:1186-1192.

Brownell AL, Livni E, Galpern W, Isacson O (1998a) In vivo PET imaging in rat of dopamine terminals reveals functional neural transplants. Ann Neurol 43:387-390.

Brownell AL, Jenkins BG, Elmaleh DR, Deacon TW, Spealman RD, Isacson O (1998b) Combined PET/MRS brain studies show dynamic and longterm physiological changes in a primate model of Parkinson disease. Nat Med 4:1308-1312.

Chen Q, Andersen AH, Zhang Z, Ovadia A, Gash DM, Avison MJ (1996) Mapping drug-induced changes in cerebral R2* by multiple gradient recalled echo functional MRI. Magn Reson Imaging 14:469-476.

Chen Q, Andersen AH, Zhang Z, Ovadia A, Cass WA, Gash DM, Avison MJ (1999) Functional MRI of basal ganglia responsiveness to levodopa in parkinsonian rhesus monkeys. Exp Neurol 158:63-75.

Chen YC, Mandeville JB, Nguyen TV, Talele A, Cavagna F, Jenkins BG (2001) Improved mapping of pharmacologically induced neuronal activation using the IRON technique with superparamagnetic blood pool agents. J Magn Reson Imaging 14:517-524.

Chen YI, Galpern WR, Brownell AL, Matthews RT, Bogdanov M, Isacson O, Beal MF, Rosen BR, Jenkins BG (1997) Detection of dopaminergic neurotransmitter activity using pharmacologic MRI: correlation with PET, microdialysis, and behavioral data. Magn Reson Med 38:389-398.

Chen YI, Brownell AL, Galpern W, Isacson O, Bogdanov M, Beal MF, Livni E, Rosen BR, Jenkins BG (1999) Detection of dopaminergic cell loss and neural transplantation using pharmacological MRI, PET and behavioral assessment. NeuroReport 10:2881-2886.

Chiueh CC, Burns RS, Markey SP, Jacobowitz DM, Kopin IJ (1985) Primate model of parkinsonism: selective lesion of nigrostriatal neurons by 1-methyl-4-phenyl-1,2,3,6-tetrahydropyridine produces an extrapyramidal syndrome in rhesus monkeys. Life Sci 36:213-218.

Choi WS, Machida CA, Ronnekleiv OK (1995) Distribution of dopamine D1, D2, and D5 receptor mRNAs in the monkey brain: ribonuclease protection assay analysis. Brain Res Mol Brain Res 31:86-94.

Devous Sr MD, Trivedi MH, Rush AJ (2001) Regional cerebral blood flow response to oral amphetamine challenge in healthy volunteers. J Nucl Med 42:535-542.

Drevets WC, Gautier C, Price JC, Kupfer DJ, Kinahan PE, Grace AA, Price JL, Mathis CA (2001) Amphetamine-induced dopamine release in human ventral striatum correlates with euphoria. Biol Psychiatry 49:81-96.

Dubowitz DJ, Bernheim KA, Chen DY, Bradley Jr WG, Andersen RA (2001) Enhancing fMRI contrast in awake-behaving primates using intravascular magnetite dextran nanopartieles. NeuroReport 12:2335-2340.

Frost JJ, Rosier AJ, Reich SG, Smith JS, Ehlers MD, Snyder SH, Ravert HT, Dannals RF (1993) Positron emission tomographic imaging of the dopamine transporter with 11C-WIN 35,428 reveals marked declines in mild Parkinson's disease. Ann Neurol 34:423-431.
Gash DM, Zhang A, Umberger G, Mahood K, Smith M, Smith C, Gerhardt GA (1999) An automated movement assessment panel for upper limb motor functions in rhesus monkeys and humans. J Neurosci Methods 89:111-117.

German DC, Manaye KF, Sonsalla PK, Brooks BA (1992) Midbrain dopaminergic cell loss in Parkinson's disease and MPTP-induced parkinsonism: sparing of calbindin-D28k-containing cells. Ann NY Acad Sci 648:42-62.

Hantraye P, Brownell A-L, Elmaleh D, Spealman RD, Wullner U, Brownell GL, Isacson O (1992) Dopamine fiber detection by [11C]-CFT and PET in a primate model of parkinsonism. NeuroReport 3:265-268.

Hemsworth BA, Neal MJ (1968) The effect of central stimulant drugs on acetylcholine release from rat cerebral cortex. Br J Pharmacol 34:543-550.

Honey GD, Suckling J, Zelaya F, Long C, Routledge C, Jackson S, Ng V, Fletcher PC, Williams SC, Brown J, Bullmore ET (2003) Dopaminergic drug effects on physiological connectivity in a human cortico-striatothalamic system. Brain 126:1767-1781.

Imbert C, Bezard E, Guitraud S, Boraud T, Gross CE (2000) Comparison of eight clinical rating scales used for the assessment of MPTP-induced parkinsonism in the Macaque monkey. J Neurosci Methods 96:71-76.

Innis RB, Malison RT, al-Tikriti M, Hoffer PB, Sybirska EH, Seibyl JP, Zoghbi SS, Baldwin RM, Laruelle M, Smith EO, et al. (1992) Amphetaminestimulated dopamine release competes in vivo for [123I]IBZM binding to the D2 receptor in nonhuman primates. Synapse 10:177-184.

Jenkins BG, Chen IY, Mandeville JB (2002) Pharmacologic magnetic resonance imaging (phMRI). In: Biomedical imaging in experimental neuroscience (van Bruggen N, Roberts T, eds), pp 155-209. Boca Raton, FL: CRC.

Lindauer U, Villringer A, Dirnagl U (1993) Characterization of CBF response to somatosensory stimulation: model and influence of anesthetics. Am J Physiol 264:H1223-H1228.

Mandeville JB, Marota JJ, Kosofsky BE, Keltner JR, Weissleder R, Rosen BR, Weisskoff RM (1998) Dynamic functional imaging of relative cerebral blood volume during rat forepaw stimulation. Magn Reson Med 39:615-624.

Mandeville JB, Jenkins BG, Kosofsky BE, Moskowitz MA, Rosen BR, Marota JJ (2001) Regional sensitivity and coupling of BOLD and CBV changes during stimulation of rat brain. Magn Reson Med 45:443-447.

Marota JJ, Mandeville JB, Weisskoff RM, Moskowitz MA, Rosen BR, Kosofsky BE (2000) Cocaine activation discriminates dopaminergic projections by temporal response: an fMRI study in rat. NeuroImage 11:13-23.

Marsden CD, Obeso JA (1994) The functions of the basal ganglia and the paradox of stereotaxic surgery in Parkinson's disease. Brain 117:877-897.

Martinez D, Slifstein M, Broft A, Mawlawi O, Hwang DR, Huang Y, Cooper T, Kegeles L, Zarahn E, Abi-Dargham A, Haber SN, Laruelle M (2003) Imaging human mesolimbic dopamine transmission with positron emission tomography. II. Amphetamine-induced dopamine release in the functional subdivisions of the striatum. J Cereb Blood Flow Metab 23:285-300.

Matsumoto N, Minamimoto T, Graybiel AM, Kimura M (2001) Neurons in the thalamic CM-Pf complex supply striatal neurons with information about behaviorally significant sensory events. J Neurophysiol 85:960-976.

Meador-Woodruff JH, Mansour A, Grandy DK, Damask SP, Civelli O, Watson Jr SJ (1992) Distribution of D5 dopamine receptor mRNA in rat brain. Neurosci Lett 145:209-212.

Nguyen TV, Brownell AL, Iris Chen YC, Livni E, Coyle JT, Rosen BR, Cavagna F, Jenkins BG (2000) Detection of the effects of dopamine receptor supersensitivity using pharmacological MRI and correlations with PET. Synapse 36:57-65.

Nurmi E, Ruottinen H, Kaasinen VJB, Haaparanta M, Solin O, Rinne JO (2000) Progression in Parkinson's disease: a positron emission tomography study with a dopamine transporter ligand [18F]CFT. Ann Neurol 47:804-808.

Piccini P, Pavese N, Brooks DJ (2003) Endogenous dopamine release after pharmacological challenges in Parkinson's disease. Ann Neurol 53:647-653.

Price JC, Drevets WC, Ruszkiewicz J, Greer PJ, Villemagne VL, Xu L, Mazumdar S, Cantwell MN, Mathis CA (2002) Sequential H(2)(15)O PET studies in baboons: before and after amphetamine. J Nucl Med 43:1090-1100. Schneider JS, Yuwiler A, Markham CH (1987) Selective loss of subpopula- 
tions of ventral mesencephalic dopaminergic neurons in the monkey following exposure to MPTP. Brain Res 411:144-150.

Stein EA (2001) fMRI: a new tool for the in vivo localization of drug actions in the brain. J Anal Toxicol 25:419-424.

Vanduffel W, Fize D, Mandeville JB, Nelissen K, Van Hecke P, Rosen BR, Tootell RB, Orban GA (2001) Visual motion processing investigated using contrast agent-enhanced fMRI in awake behaving monkeys. Neuron 32:565-577.

Villringer A, Rosen BR, Belliveau JW, Acerman JL, Lauffer RB, Buxton RB, Chao YS, Wedeen VJ, Brady TJ (1988) Dynamic imaging with lanthanidechelates in normal brain: contrast due to magnetic susceptibility effects. Magn Reson Med 6:164-174.
Wechsler LR, Savaki HE, Sokoloff L (1979) Effects of d-and l-amphetamine on local cerebral glucose utilization in the conscious rat. J Neurochem 32:15-22.

Zaharchuk G, Mandeville JB, Bogdanov Jr AA, Weissleder R, Rosen BR, Marota JJ (1999) Cerebrovascular dynamics of autoregulation and hypoperfusion. An MRI study of CBF and changes in total and microvascular cerebral blood volume during hemorrhagic hypotension. Stroke 30:2197-2205.

Zhang Z, Andersen A, Grondin R, Barber T, Avison R, Gerhardt G, Gash D (2001) Pharmacological MRI mapping of age-associated changes in basal ganglia circuitry of awake rhesus monkeys. NeuroImage 14:1159-1167. 